\title{
An acute dose, randomized trial of the effects of CDP-Choline on Mismatch Negativity (MMN) in healthy volunteers stratified by deviance detection level
}

Verner Knott ${ }^{1,2,3,4^{*}}$, Danielle Impey ${ }^{2}$, Joelle Choueiry ${ }^{3}$, Dylan Smith ${ }^{3}$, Sara de la Salle ${ }^{2}$, Salman Saghir ${ }^{2}$, Meaghan Smith ${ }^{2}$, Elise Beaudry², Vadim Ilivitsky ${ }^{4}$ and Alain Labelle ${ }^{4}$

\author{
* Correspondence: \\ Verner.Knott@theroyal.ca \\ 'University of Ottawa institute of \\ Mental Health Research, Royal \\ Ottawa Mental Health Care Centre, \\ 1145 Carling Avenue, Ottawa, \\ Ontario K1Z 7 K4, Canada \\ ${ }^{2}$ School of Psychology, University of \\ Ottawa, Ottawa, ON, Canada \\ Full list of author information is \\ available at the end of the article
}

\begin{abstract}
Background: Alpha 7 nicotinic acetylcholine receptors (a7 nAChR) are prioritized molecular targets for the development of new pharmacological treatments for impaired cognition in schizophrenia. The use of schizophrenia-associated biomarkers both as endpoints and for segmentation of homogeneous populations for early detection of cognitive enhancing agents has been advanced to enhance the drug discovery process.

Methods: In this study, the mismatch negativity (MMN) event-related brain potential (ERP), considered one of the few fully developed biomarkers in schizophrenia, was employed: a) to stratify 24 healthy volunteers into subgroups exhibiting low, medium, or high auditory sensory discrimination based on pre-attentive detection of deviant auditory features, and b) to assess their acute response to a low (500 mg) and moderate dose $(1000 \mathrm{mg})$ of CDP-choline, a dietary supplement with selective agonist actions at a7 nAChRs.
\end{abstract}

Results: No significant whole group effects were observed with CDP-choline, and MMN changes were observed only with analysis of subgroups. The effects of CDP-choline interacted both with deviant type and auditory deviance detection level, with individuals exhibiting low MMNs showing enhanced amplitudes, while those with high MMNs evidenced reduced amplitudes with acute dosing of CDP-choline.

Conclusions: These preliminary findings of improved auditory deviance detection with CDP-choline in our biomarker-defined healthy surrogate group supports the contention that a7 nicotinic cholinergic agonism be studied as a potential pro-cognitive mechanism in patients with schizophrenia.

Keywords: Alpha 7 nicotinic acetylcholine receptor, a7 nAChR, Nicotine, CDP-choline, Event-related potential, ERP, Deviance detection, Mismatch negativity, MMN, Schizophrenia

\section{Background}

Nicotinic acetylcholine receptors (nAChR) have been implicated in cognitive functioning and preclinical studies have strongly supported attentional enhancing effects of agonists acting at $\alpha 7$ and $\alpha 4 \beta 2 \mathrm{nAChR}$ subunits in the hippocampus and prefrontal cortex (Bentley et al. 2011; dos Santos and Granon 2012; Levin et al. 2006; Mansvelder et al. 2006; Sarter et al. 2009; Wallace and Bertrand 2013a, b). The prototypical nAChR

(c) 2015 Knott et al.; licensee BioMed Central. This is an Open Access article distributed under the terms of the Creative Commons Attribution License (http://creativecommons.org/licenses/by/4.0), which permits unrestricted use, distribution, and reproduction in any medium, provided the original work is properly credited. The Creative Commons Public Domain Dedication waiver (http:// creativecommons.org/publicdomain/zero/1.0/) applies to the data made available in this article, unless otherwise stated. 
agonist nicotine, which is the main psychoactive agent in tobacco, has been shown to reverse withdrawal-induced task performance impairments in smokers (Heishman et al. 1994) and has exerted positive effects in multiple cognitive domains, including motor abilities, attention and memory, when administered in single "smoking doses" to nonsmokers (Heishman et al. 2010).

Smoking prevalence in schizophrenia (SZ), a disorder in which cognitive disturbances are core features and are relatively nonresponsive to available antipsychotic treatments (Gold 2004; Marder and Fenton 2004), ranges from 45 to $88 \%$, compared to $<20 \%$ in the general population (Dickerson et al. 2013; Morisano et al. 2013). Observed in animal models of SZ and in SZ patients, transient improvements in sensory, attentional, mnemonic and executive functions with acute nicotine/nAChR agonist treatment (D'Souza and Markou 2012; Kucinski et al. 2011; Leiser et al. 2009; Olincy and Freedman 2012; Radek et al. 2010) have collectively promoted the hypothesis of smoking in SZ as self-medication for cognitive deficits mediated via nAChR pathophysiology (Kumari and Postma 2005; Wing et al. 2012; Winterer 2010).

Converging lines of research have prioritized the $\alpha 7 \mathrm{nAChR}$ as one of the most promising targets in the development of cognitive pharmacotherapies for patients with SZ (Buchanan et al. 2007; Green 2007). Found both in SZ patients and their biological relatives, a sensory gating deficit (inability to inhibit responses to redundant, irrelevant stimuli) indexed by suppression of the auditory P50 event-related potential (ERP) has shown genetic linkage to the locus on chromosome 15q13-14, which codes (i.e., CHRNA7) for the $\alpha 7$ nAChR subunit (Freedman et al. 1997; Raux et al. 2002). Possibly reflecting single nucleotide changes within promoter regions of CHRNA7 (Leonard et al. 2002), diminished numbers of apparently structurally intact $\alpha 7 \mathrm{nAChRs}$ have been shown in the hippocampus (Freedman et al. 1995), frontal cortex (Guan et al. 1999) and the nucleus reticularis thalami (Court et al. 1999) of SZ postmortem brains. Results from clinical trials of novel $\alpha 7$ molecules in SZ patients have been mixed (Young and Geyer 2013). DMXB-A (a.k.a. GTS-21), the first $\alpha 7$ partial agonist to be developed, evidenced pro-gating and pro-cognitive properties in an acute dosing paradigm (Olincy et al. 2006) but failed to impact cognitive performance with chronic (4-weeks) treatment (Freedman et al. 2008) and similar null effects were recently observed in an 8week study with the $\alpha 7$ nAChR partial agonist, RG3487 (Umbricht et al. 2014). This contrasts with proof-of-concept trials with partial $\alpha 7$ agonists EVP-6124 (Hilt et al. 2011) and TC-5619 (Lieberman et al. 2013), both showing improved cognition in SZ patients at week 12. Reviews of these and other $\alpha 7$ molecules under various stages of clinical development have tentatively underscored the potential of $\alpha 7$ modulators as add-on therapy to antipsychotics, but point to the need for a better understanding of brain functions regulated by this receptor system (Bencherif et al. 2012; Geerts 2012; Hurst et al. 2012; Wallace and Bertrand 2013a; Young and Geyer 2013).

Choline, an amine that is a precursor for the synthesis of acetylcholine, is an essential nutrient that has many biological functions, and in addition to being a lipid component involved in cell membrane protection and repair (Blusztajn 1998; Zeisel and Blusztujn 1994; Zeisel 2000) is a selective full agonist at the $\alpha 7 \mathrm{nAChR}$ (Albuquerque et al. 1998; Alkondon et al. 1999; Fayuk and Yakel 2004). As gestational choline supplementation enhances gating and cognition in adult offspring mice (Meck and Williams 2003; Stevens et al. 2008, 2014) and increases rates of efficient sensory inhibition (P50 suppression) in 
human infants whose mothers' diets during pregnancy were supplemented with choline (Ross et al. 2013), dietary choline supplementation has been promoted as a possible preventive intervention for cognitive deficits in individuals considered to be "at risk" for SZ (Corriveau and Glenn 2012; Freedman 2014).

Choline's potential to address cognitive impairment associated with SZ has received only minimal attention. 5'-citidine diphosphocholine or CDP-choline (citicoline) is a dietary supplement which acts as a key intermediate in the biosynthesis of phosphatidylcholine from choline (Secades et al. 1995). CDP-choline has been shown to improve impaired cognition associated with chronic ischaemia, head trauma, dementia and normal aging (Alvarez-Sabin and Roman 2011; Conant and Schauss 2004; Davalos et al. 2012; Fioravanti and Buckley 2006; Garcia-Cobos et al. 2010; Secades 2012). In a 16week trial combining CDP-choline with the positive allosteric modulator (PAM) of the $\alpha 7$ and $\alpha 4 / \beta 2$ nAChRs, galantamine, clinical symptoms of SZ patients were unaffected but overall functional level of patients was increased, as was performance on a test of free verbal recall (Deutsch et al. 2013). CDP-choline in this study was administered in the clinically recommended maximum dose range (2000 $\mathrm{mg} /$ day) but nAChR agonist effects often display an inverted U-shaped dose response curve, with maximal effects being observed at low and ultralow doses (Castner et al. 2011; Hahn et al. 2002; Werkheiser et al. 2011).

The primary objective of this present study is to investigate the acute group-wise effects of low-to-moderate doses (500 mg, $1000 \mathrm{mg}$ ) of CDP-choline in a sample of healthy volunteers. Prior to the implementation of costly and time consuming CDPcholine clinical trials in patients, this study will employ a rationale strategy advocated for the early identification of pro-cognitive drug actions, which involves the use of a within-subject challenge dose design (placebo vs. active) in biomarker-identified subgroups (surrogate populations) that have only a limited symptom profile but without the confounds (e.g. medication, disease chronicity, symptom variability) associated with the disorder (Chou et al. 2012; Koychev et al. 2012). Cortical cholinergic input is required for normal auditory sensory and perceptual processing (Leach et al. 2013), deficits of which are highly frequent in SZ and are indexed by ERP biomarkers (Javitt 2009). The mismatch negativity (MMN) ERP, which can probe dysfunction in basic perceptual processes isolated to primary sensory regions and can be modeled in preclinical studies, fulfills criteria for use as an endophenotypic marker (Gottesman and Gould 2003) of the SZ disease (Belger et al. 2012; Takahashi et al. 2013), and is considered one of the few fully developed, "already mature" electrophysiologic biomarkers (Butler et al. 2012; Green et al. 2009), allowing for unique opportunities for use as a translational biomarker in SZ drug discovery (Javitt et al. 2008). An essential feature of this mature biomarker is its substantial test-retest reliability, which exceeds 0.8 in healthy volunteers and patients and is of particular importance in clinical trials with repeated measures designs (Light et al. 2012).

Auditory MMN, requiring no behavioural response or attention, is elicited as a frontocentral maximum negative peak on the scalp (at 120-250 ms) when a sequence of repetitive stimuli is interrupted infrequently by deviant stimuli differing in any physical or abstract manner. It is the earliest neural sign of acoustic change detection, and although there are different explanations for the MMN (Fishman 2013; May and Tiitinin 2010), the "sensory memory" hypothesis proposes that it is an automatic, pre-attentive 
process that results from the comparison of standard and deviant memory traces of stimulus features in brief (lasting up to $30 \mathrm{sec}$ ) auditory ("echoic") sensory memory (Näätänen et al. 2011). Greater discrepancies between deviant and standard memory traces (i.e., increasing deviance) are associated with larger MMN amplitudes and shorter latencies, both measures being correlated with behavioural discrimination of sounds (Näätänen et al. 2012). Frequently found in SZ (vs. bipolar disorder), deficits in MMN generation are also observed in unaffected family members and first-episode patients (Sumiyoshi et al. 2013; Nagai et al. 2013a, 2013b; Näätänen et al. 2014), and are exhibited in patients in response to a variety of auditory deviants, although duration deviant MMNs are viewed as being more trait specific for this disorder, while pitch and intensity deviant MMNs have shown different temporal changes over the course of the illness (Näätänen and Kahkonen 2008; Todd et al. 2008). Impaired MMN generation in SZ is linked to structural (Rasser et al. 2011; Salisbury et al. 2007) and functional (Javitt 2000; Light and Braff 2005) impairments in the auditory sensory cortex and correlates with negative symptoms and poor executive functioning (Kiang et al. 2007; Näätänen et al. 2004; Turetsky et al. 2009; Umbricht et al. 2006) as well as deficits in social/occupational functioning (Lee et al. 2014; Light and Braff 2005), while in healthy volunteers, the greater the MMN amplitude, the stronger the functional status of the individual (Light et al. 2007).

MMN is relatively unaffected by antipsychotics, although we have shown it to correlate with clozapine dose (Horton et al. 2011) which, among its other actions, indirectly increases acetylcholine synaptic transmission (Ichikawa et al. 2002) and cortical glutamate (Tanahashi et al. 2012). Strongly dependent on glutamatergic signaling, MMN is attenuated in rats, monkeys and healthy adults with high-affinity NMDA (N-methyl-Daspartate)-type glutamate receptor antagonists (Javitt et al., 1996; Tikhonravov et al. 2008; Umbricht et al. 2000) such as ketamine which, when combined with nicotine, fails to disrupt MMN in some (Knott et al. 2012) but not all investigations (Mathalon et al. 2014). Most frequently investigated in healthy participants with frequency deviants, nicotinic stimulation has resulted in negative (Knott et al. 2006, 2011), diminishing (Knott et al. 2009) and enhancing effects on MMN amplitude (Dunbar et al. 2007), with the latter positive outcome also being shown with pattern (Baldeweg et al. 2006), temporal (Martin et al. 2009) and visual deviants (Fisher et al. 2010). Such response variability is also seen in the relatively few studies in SZ, with nicotine not affecting frequency deviant MMN (Dulude et al. 2010; Inami et al. 2007), shortening latency of intensity-deviant MMN (Fisher et al. 2012) and in our work, "normalizing" durationdeviant MMN by increasing the diminished MMN in patients to a level comparable to that seen in healthy volunteers (Dulude et al. 2010).

Contributing to variability in MMN are individual difference in age (Ruzzoli et al. 2012), intelligence (Bazana and Stelmack 2002), gender and personality (Matsubayashi et al. 2008). These factors, as well as genetic influences, and inter-subject differences in smoker vs. nonsmoker status, pre-drug state, and functional level are also significant sources of individual variability in nicotine response (Gilbert and Gilbert 1995; Kupferschmidt et al. 2010; Li et al. 2009; Perkins 1995; Perkins 2009; Poltavski and Petros 2005). Frequently shown in animal models and in human studies, baseline-dependent differences have influenced behavioural, cognitive, and subjective mood responses to nicotine (Perkins 1999). More recently, baseline-dependent neural responses to nicotine have been evidenced with two widely used biomarkers of SZ, namely, P50-indexed auditory sensory gating 
(Knott et al. 2010, 2013) and MMN-indexed auditory sensory discrimination (Knott et al. 2014), with both biomarkers being enhanced by acute nicotine, but only in individuals with relatively diminished, SZ-like P50 gating and MMN baseline responses. In individuals with high baseline gating and discriminability, P50 suppression and MMN amplitude were either not affected, or were attenuated by single dose nicotine treatment. Only two reports have examined the effects of $\alpha 7 \mathrm{nAChR}$ medications on MMN, both being conducted in SZ patients. While JNJ-39393406, an $\alpha 7$ PAM, failed to alter MMN (Winterer et al. 2013), the $\alpha 7$ partial agonist EVP-6124 increased the frequency deviant MMN in a dosedependent manner (Preskorn et al. 2014).

Taking advantage of demonstrated, biomarker-defined inter-individual heterogenecity in sensory response to nicotinic receptor stimulation, this study will carry out an exploratory analysis on the possible relationship between endogenous choline and response to CDP-choline by examining how individuals stratified on the basis of MMN amplitude compare in their response to an acute low and moderate dose of CDPcholine. In line with previous suggestions of an inverted U-shaped response characterizing cognitive effects of nicotinic stimulation (Newhouse et al. 2004), and based on our recent study with the prototypical nAChR agonist, nicotine, which enhanced auditory deviance detection in individuals with small amplitude MMNs and attenuated deviance detection in those with higher amplitude MMNs (Knott et al. 2014), we hypothesized that both doses of CDP-choline (vs. placebo) would increase deviance detection $(\mathrm{MMN})$ in individuals exhibiting relatively diminished detection ability (i.e. low baseline MMN amplitudes) and exert negative or diminishing effects in those with relatively moderate, optimal, or above optimal detection ability (i.e., medium or high baseline $\mathrm{MMN}$ amplitudes). As the lower dose is likely to be associated with less $\alpha 7$ receptor desensitization, MMN enhancement is expected to be greater with $500 \mathrm{mg}$ (vs. $1000 \mathrm{mg}$ ) of CDP-choline. The study limited sample recruitment to healthy, young, male adults with a non-smoking history in order to reduce other sources of interindividual variability.

\section{Methods}

The study protocol was approved by the Research Ethics Boards of the Royal Ottawa Health Care Group and the University of Ottawa and was carried out in accordance with the Canadian Tri-Council Policy Statement for Ethical Conduct for Research Involving Humans. All volunteers provided written consent prior to participation and were compensated $\$ 200$ CAD for their time and effort.

\section{Participants}

Recruited by advertisements, the study sample consisted of 24 healthy, right handed males between 18-40 years of age. Volunteers were initially screened by telephone and then by personal interview. Based on history and physical exam, all participants were medically and neurologically normal and, as screened with the SCID-NP (Structured Clinical Interview - Non-Patient version for DSM-IV: Williams et al. 1992) and FIGS (Family Interview for Genetic Studies: Maxwell, 1992), had no personal or immediate (first degree biological relatives) family history of psychiatric disorders. Participants were nonsmokers, having smoked less than 100 cigarettes in their lifetime and none in 
the past year, and exhibited an expired air carbon monoxide level $<3 \mathrm{ppm}$, which is consistent with a nonsmoker status (Cropsey et al. 2006). None of the participants reported any use of smokeless tobacco products (e.g. nicotine gum or patch).

\section{Design}

Participants were assessed in three separate sessions (placebo and two doses of CDPcholine) within a randomized, double-blind, crossover design. Session order was counterbalanced with respect to the total sample (not within each subgroup, which were designated at study completion), so that the 6 possible randomization orders were repeated four times across 24 participants. Approximately 8-12 days separated the sessions in order to allow for CDP-choline elimination.

\section{Procedure}

Test sessions were conducted between 9:00 a.m. - 1:00 p.m., each following overnight abstinence from smoking/nicotine, caffeine, alcohol, drugs/medication and food. Three hours after treatment administration, the time of maximal drug absorption, ERPs were recorded following which, adverse events and vital signs were evaluated for safety purposes.

\section{CDP-choline}

Participants were administered CDP-choline orally in two active doses, $500 \mathrm{mg}(2 \times$ $250 \mathrm{mg}$ capsules $)$ and $1000 \mathrm{mg}(4 \times 250 \mathrm{mg}$ capsules). In study trials, clinically effective CDP-choline has been administered orally and by injection with doses ranging from $500-4000 \mathrm{mg} /$ day, although generally efficacy has not substantially improved beyond $2000 \mathrm{mg} /$ day. When administered orally, it is absorbed almost completely, with bioavailability being $92-94 \%$ and approximately the same as when administered intravenously (Agut et al. 1983). Single oral doses dose-dependently raise plasma levels and increase brain choline levels, with peripheral levels rising slowly and peaking at $3-$ $5 \mathrm{hr}$, and with elimination half-life extending up to $56 \mathrm{hr}$ (Wurtman et al. 2000). In studies with CDP-choline administered up to 12 months, it showed excellent tolerability and safety, with a few transient (never severe) adverse effects (e.g. stomach pain, diarrhea) (Conant et al. 2004; Fioravanti et al. 2006; Saver 2008). A "double dummy" procedure was used with participants being administered 4 capsules in each session so that the dose remained blind (e.g. 2 placebo capsules and $2 \times 250 \mathrm{mg}$ capsules comprised the $500 \mathrm{mg}$ CDP-choline condition). The placebo capsules (containing cellulose) physically matched the active capsules.

\section{Paradigm}

During the MMN paradigm participants viewed a silent video (The Blue Planet by BBC, 2001). In the optimal MMN paradigm (Näätänen et al. 2004), auditory tonal stimuli of $70 \mathrm{~dB}$ sound pressure level (SPL) were presented binaurally through headphones and consisted of standard ( $\mathrm{p}=0.5$ ) stimuli (composed of 500, 1000, and $1500 \mathrm{~Hz}$ pure tones of $75 \mathrm{~ms}$ duration) that were randomly intermixed with deviant $(\mathrm{p}=0.5)$ stimuli. Stimulus onset asynchrony (SOA) was fixed at $500 \mathrm{~ms}$. The deviant tones differed from the standard tones in terms of frequency, duration, intensity, perceived location of sound origin, or contained a silent gap in the middle of the tone (i.e. gap deviants). The 
duration deviant was only $25 \mathrm{~ms}$ in duration (instead of $75 \mathrm{~ms}$ ). Half of the frequency deviants were $10 \%$ lower (composed of 450, 900, and $1350 \mathrm{~Hz}$ partials) and the other half were $10 \%$ higher (composed of 550, 1100, and $1650 \mathrm{~Hz}$ partials). Half of the intensity variants were at $80 \mathrm{~dB}$ and the other half at $60 \mathrm{~dB}$. A change in perceived location was created by creating an $800 \mu$ s time difference between the channels, leading to a change in location of approximately $90^{\circ}$. Half of the deviants had a $800 \mu$ s delay in the right channel while the other half was in the left channel. In the gap deviants $7 \mathrm{~ms}$ (including a $1 \mathrm{~ms}$ rise and fall) were removed from the middle of the standard stimulus. Three blocks of these stimulus sequences were presented for a total of 15 min (5535 stimuli). Each sequence started with a 15 standard tones, followed by a sequence in which every second tone was a standard $(\mathrm{p}=0.5)$ and every other tone was one of the five deviants $(\mathrm{p}=0.1 \mathrm{each})$. One deviant of each category was presented once every five deviants. No two deviants were presented consecutively.

\section{Recordings}

ERPs were recorded with a cap embedded with $\mathrm{Ag}^{+} / \mathrm{Ag}^{+} \mathrm{Cl}^{-}$electrodes (EasyCap, Herrching-Brieibrunn, Germany) positioned on 8 scalp locations, including left, right, and middle frontal $\left(\mathrm{F}_{3}, \mathrm{~F}_{4}, \mathrm{~F}_{\mathrm{Z}}\right)$; left, right, and middle central $\left(\mathrm{C}_{3}, \mathrm{C}_{4}, \mathrm{C}_{\mathrm{Z}}\right)$ and both middle parietal $\left(\mathrm{P}_{\mathrm{Z}}\right)$ and occipital $\left(\mathrm{O}_{\mathrm{Z}}\right)$ sites, according to the 10-10 system. An electrode on the nose served as reference and a ground electrode was positioned above the $\mathrm{F}_{\mathrm{Z}}$ site. Electrodes were placed above and below the right eye to record vertical electrooculographic (VEOG) activity and at the external canthus of both eyes to measure horizontal electrooculographic (HEOG) activity. Electrical recordings were carried out using a Brain Vision V-8 Amp (Brain Products GmbH, Munich, Germany) amplifier and Brain Vision Recorder (Brain Products GmbH, Munich, Germany) software. Electrical activity was sampled at $500 \mathrm{~Hz}$, with amplifier bandpass filters set at 0.1 $100.0 \mathrm{~Hz}$. Electrode impedances were kept below $5 \mathrm{k} \Omega$. Off-line analysis was performed with Brain Vision Analyzer software (Brain Products, GmbH, Munich, DE). For each stimulus, electrical epochs of $500 \mathrm{~ms}$ duration (beginning $100 \mathrm{~ms}$ prior to stimulus onset) were digitally filtered (0.1-20 Hz) (Sabri \& Campbell 2002), ocular (Gratton et al. 1983) and baseline corrected (relative to the pre-stimulus segment), and only epochs with EEG voltages below $75 \mu \mathrm{V}$ were used for final ERP averages, which were constructed separately for the standard and each deviant stimulus type at each electrode site. Waveforms for the low and high frequency deviants, those for the low and high intensity deviants, and those for the right and left location, were averaged together. MMNs were analyzed with difference waveforms, which were derived by digital pointby-point subtraction of the standard stimulus values from those elicited by each of the deviant stimuli. Based on visual inspection of the grand average waveforms (i.e., averaged across all participants), MMN amplitude was measured as the most negative peak between 120-250 ms. MMN amplitude and latency (time to reach peak MMN) were measured at the midline frontal site $\left(\mathrm{F}_{\mathrm{Z}}\right)$, within the region exhibiting maximal MMN amplitude. Amplitude of the N1 component (peak negativity between 90-120 ms) elicited by the standard stimulus was also measured (from $\mathrm{F}_{\mathrm{Z}}$ ) to determine whether or not MMN modulation by CDP-choline was associated with alterations in sensory registration. 


\section{Symptoms}

Adverse events were evaluated by having participants complete a 5-point Likert scale ( 0 = none, $4=$ severe) on common symptoms (e.g., jitteriness, headache, nausea, vomiting) associated with nicotinic stimulation (adapted from Harkrider and Hedrick 2005).

\section{Vitals}

Heart rate (HR) (beats per minute $[\mathrm{bpm}]$ ), systolic (SBP) and diastolic (DBP) blood pressure (milliliters per milligram of mercury $[\mathrm{ml} / \mathrm{mgHg}]$ ) were measured before and after gum chewing, with the participants in a sitting position. These measures were only used for safety purposes.

\section{Analysis}

Statistical analysis was carried out with the Statistical Package for Social Sciences (SPSS Inc., Chicago, IL). In order to reduce Type I statistical errors, analyses was limited to MMNs derived from frontal electrodes, where amplitude is maximal. In the primary group-wise analyses with the entire sample $(\mathrm{N}=24)$, the five deviant MMNs were analyzed in separate repeated measures analysis of variance (ANOVA) with treatment (3 levels: placebo, $500 \mathrm{mg}, 1000 \mathrm{mg}$ ) and site $\left(\mathrm{F}_{3}, \mathrm{~F}_{\mathrm{Z}}, \mathrm{F}_{4}\right)$ as within-subject factors. In the secondary, exploratory analyses, separate mixed ANOVAs were carried out with the 5 deviant MMNs, with treatment and site as within-subject factors and group (3 levels: low, medium and high amplitude MMN participants) as a between-subject factor. Using placebo session data, groups were derived with respect to each of the $5 \mathrm{MMN}$ deviant types by ranking midline frontal $\left(\mathrm{F}_{\mathrm{Z}}\right)$ baseline (placebo) amplitudes of participants from the smallest to largest and designating the two groups of 8 individuals with the extreme low and high amplitudes as the "low" and "high" groups, respectively. The remaining 8 participants were designated as the "medium" group. This same stratification procedure has been used in our previous work on nicotine and sensory gating (Knott et al. 2013). The ANOVAs also included an examination of order effects, but these were not evident with any of the study findings. Greenhouse-Geisser correction was applied to within-subject factors with more than 2 levels and, regardless of whether significance $(p>0.05)$ was observed with main or interaction effects, follow-up comparisons (Bonferroni-corrected) were conducted to test a priori hypotheses. Of primary interest in the exploratory analyses were the effects of treatment and group interaction effects, testing significance of CDP-choline (vs. placebo) effects within each group. If site was not involved in the interactions, comparisons were carried out with MMN values at the frontal midline $\left(\mathrm{F}_{\mathrm{Z}}\right)$ site. Additional post-hoc analyses were also carried out to further clarify the source of interaction effects. Adverse events and vital signs were analyzed with similar mixed ANOVAs but without the site factor.

The use of placebo MMN scores in the exploratory analyses both for representing the best point estimate of a given individuals 'usual' MMN (for subgrouping) and for inclusion in the mixed ANOVA model possibly introduced a regression toward the mean bias (Barnett et al. 2005) in the findings (e.g. an individual who exhibits a smaller MMN in the low baseline group would be more likely to show a higher amplitude score in the next session, even if no drug was administered in the session). Since regression to the mean effects would be expected regardless of whether we segmented participants 
into subgroups with either placebo or CDP-choline session MMN scores, we ran two additional sets of mixed ANOVAs using the $500 \mathrm{mg}$ and $1000 \mathrm{mg}$ session data to subgroup our participants.

\section{Results}

Grand averaged raw midline $\left(\mathrm{F}_{\mathrm{Z}}, \mathrm{C}_{\mathrm{Z}}, \mathrm{P}_{\mathrm{Z}}\right)$ waveforms elicited by the 5 deviant and standard stimuli are shown in Figure 1, and grand average difference waveforms (deviant waveform minus standard waveform) for each deviant are displayed in Figure 2, along with the topographic distribution maps of peak MMN activity associated with each deviant type. Robust MMN components were elicited by all deviants, with maximum amplitude being shown at frontal electrodes.

Figure 3 displays the grand averaged MMNs for each deviant in the 3 segmented groups. In order to establish the presence of an MMN in the low baseline amplitude group, amplitudes at $\mathrm{F}_{\mathrm{Z}}$ to all deviants in the placebo condition were compared to zero using a $t$-test. Amplitudes and 2-tailed $t$-test statistics are summarized in Table 1. Except for the MMN elicited by the gap deviant, MMN amplitudes for all deviants in the low baseline group were significantly different from zero.

\section{Duration MMN}

In the primary group-wise analysis, treatment effects were not significant but a site effect emerged [F, $(2,40)=13.80, p<0.001]$, with amplitudes at Fz $>$ F4 $>$ F3 $(p<0.05)$.

Analysis yielded significant group $[\mathrm{F},(2,21)=11.01, p<0.01]$ and group $\mathrm{x}$ treatment interaction effects $[\mathrm{F}(4,36)=4.81, p<0.005]$ for amplitude. Grand-average midfrontal $\left(\mathrm{F}_{\mathrm{Z}}\right)$ difference waveforms for each deviant and treatment, in each group are shown in

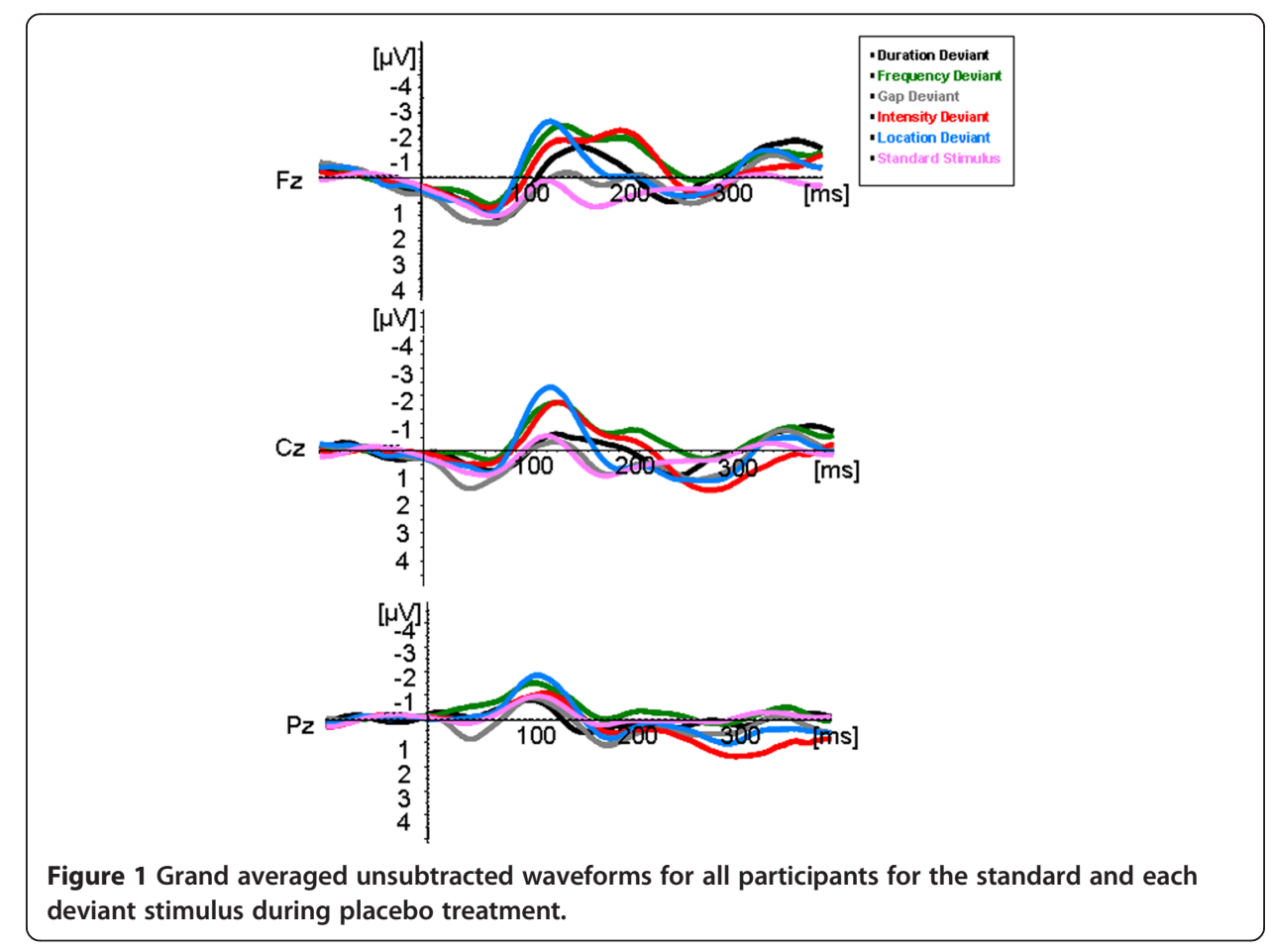




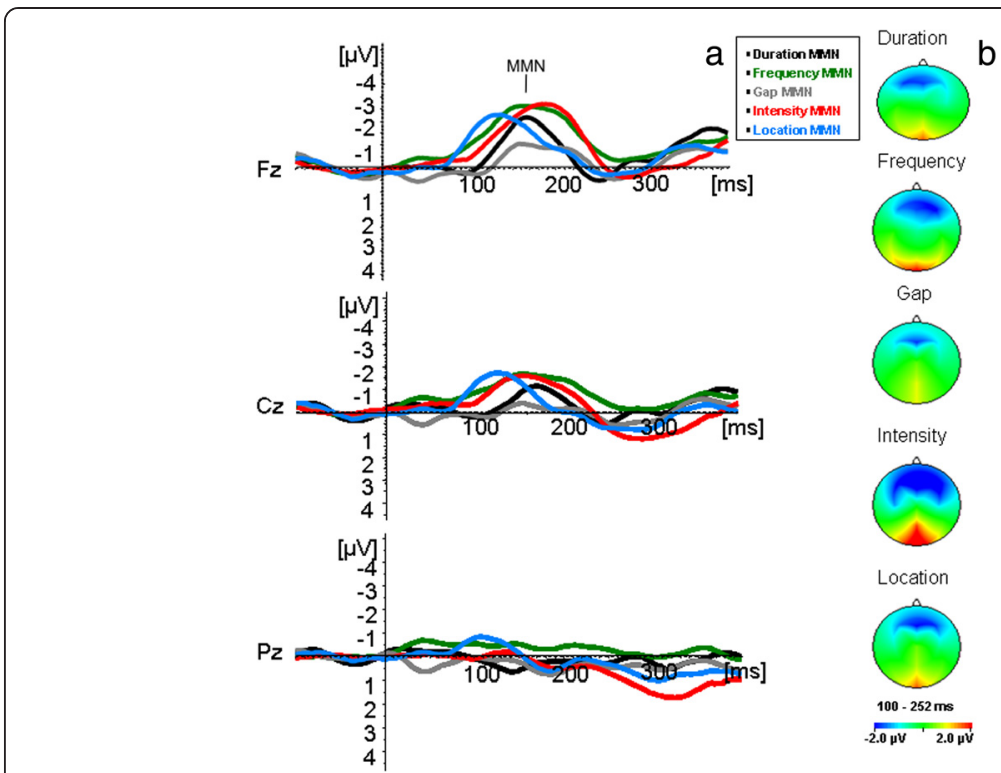

Figure 2 Grand averaged waveforms (a) and their scalp voltage distributions (b) for all participants for each deviant in the placebo session.

Figure 4. Treatment comparisons within the low baseline amplitude group found significantly larger MMNs with the $500 \mathrm{mg}(p<0.01)$ and $1000 \mathrm{mg}$ dose of CDP-choline $(p<0.05)$ compared to placebo. No significant treatment differences were observed in the medium baseline amplitude group, but in the high baseline amplitude group both $500 \mathrm{mg}(p<0.05)$ and $1000 \mathrm{mg}$ CDP-choline doses $(p<0.01)$ produced significantly smaller MMNs compared to placebo.

Post-hoc comparisons showed all groups differed from each other in the placebo session $(p<0.01)$, and while only medium and high baseline amplitude groups were significantly different in the $500 \mathrm{mg}$ dose session $(p<0.05)$, none of the groups differed from each other in the $1000 \mathrm{mg}$ dose session.

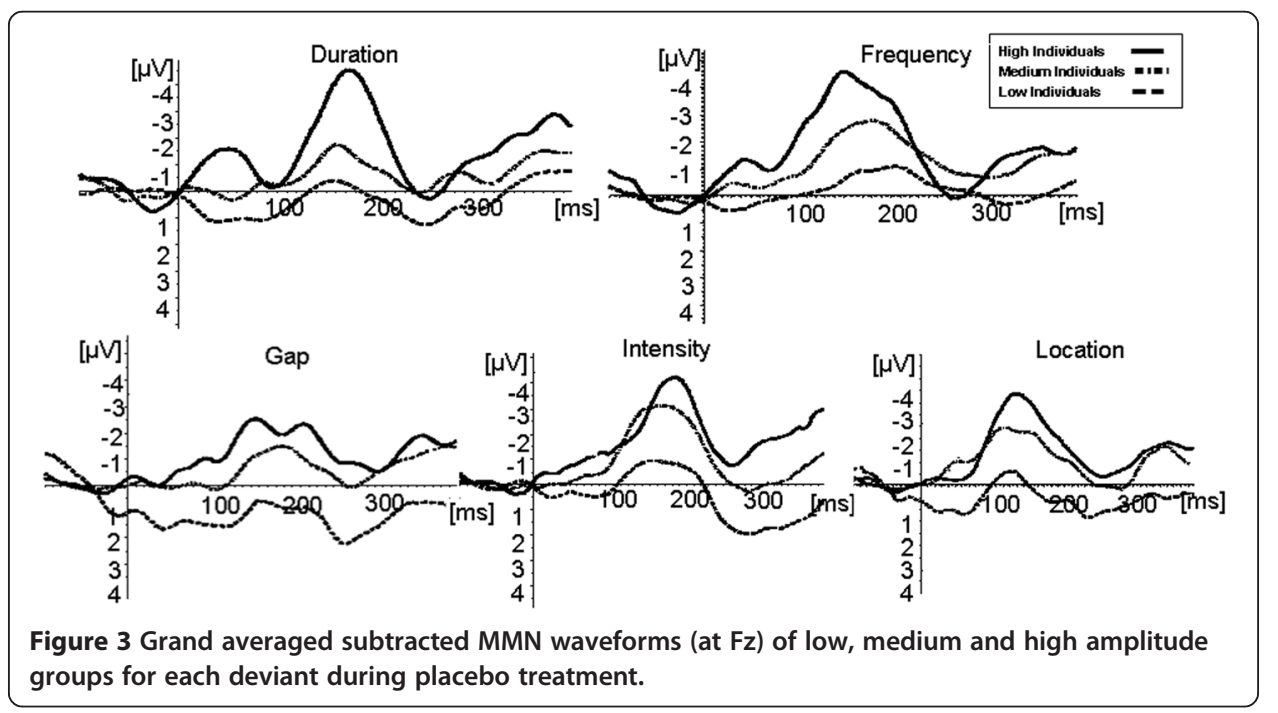


Table 1 Mean MMN amplitudes ( \pm SE) at $F_{Z}$ plus $t$-statistic and significance values resulting from 2-tailed comparison of means against zero for all placebo derived deviants in the low amplitude group

\begin{tabular}{llll}
\hline Deviant & Mean amplitude $( \pm$ SE) & $\boldsymbol{t}$ value & Significance \\
\hline Duration & $-0.67 \mu \mathrm{V}(0.54)$ & -3.53 & $p=.010$ \\
Frequency & $-1.18 \mu \mathrm{V}(1.09)$ & -3.05 & $p=.019$ \\
Gap & $0.95 \mu \mathrm{V}(0.78)$ & 0.35 & $p=.740$ \\
Intensity & $-1.48 \mu \mathrm{V}(1.15)$ & -3.64 & $p=.008$ \\
Location & $-1.01 \mu \mathrm{V}(0.91)$ & -3.14 & $p=.016$ \\
\hline
\end{tabular}

No significant main or interaction effects were observed for MMN latency.

\section{Frequency MMN}

Group-wise analysis yielded no treatment effects, but site was significant $[\mathrm{F}(2,42)=$ 5.04, $p<0.02]$, with amplitudes at Fz $>\mathrm{F} 4>\mathrm{F} 3(p<0.05)$.

Amplitude analysis resulted in a significant group [F $(2.21)=8.28(p<0.003]$ effect and a non-significant trend for a group $\mathrm{x}$ treatment interaction $[\mathrm{F}=(4,36)=2.39$, $p<0.08]$. As shown in Figure 4, treatment comparisons failed to show any CDPcholine effects in either low or medium baseline amplitude groups, but MMNs were significantly reduced in the high baseline amplitude group with the $500 \mathrm{mg}$ dose compared to placebo $(p<0.05)$.

Groups were significantly different from each other in the placebo session $(p<0.01)$ but not during the two active treatment sessions.

No significant effects were observed for MMN latency.

\section{Gap MMN}

Group-wise analysis did not show a treatment effect but site was significant $[\mathrm{F}(2,42)=$ $12.57, p<0.001]$, with amplitudes at Fz $>$ F4 $>$ F3 $(p<0.05)$.

MMN elicited by the gap deviants was affected by group [F $(2,21)=23.89, p<.001]$ and a group $x$ treatment interaction $[F(4,36)=3.02, p<0.05]$. Shown in Figure 4, treatment comparisons within each group showed a trend for the $500 \mathrm{mg}$ dose to increase MMN in the low baseline amplitude group $(p<0.08)$, while in the high baseline amplitude group MMN reduction was seen with the $500 \mathrm{mg}$ dose $(p<0.05)$ and approached significance with the $1000 \mathrm{mg}$ dose $(p<0.06)$.

All groups were significantly different from each other in the placebo $(p<0.05)$ and $1000 \mathrm{mg}$ dose session $(p<0.05)$ but while amplitudes of the low baseline group were significantly smaller than those of the medium and high baseline groups during the $500 \mathrm{mg}$ dose session $(p<0.05)$, they were similar in the medium and high baseline groups. No group, treatment or interaction effects were observed for MMN latency.

\section{Intensity MMN}

Group-wise analysis showed no treatment effect but site was significant $[\mathrm{F}(2,42)=$ $12.48, p<0.001]$, with amplitudes at $\mathrm{Fz}>\mathrm{F} 4>\mathrm{F} 3(p<0.05)$.

Group $[\mathrm{F}(2,21)=4.47, p, 0.03]$ and group $\mathrm{x}$ treatment interaction effects $[\mathrm{F}(4,36)=$ 4.92, $p<0.04$ ] were found for intensity MMN. As displayed in Figure 4, treatment 


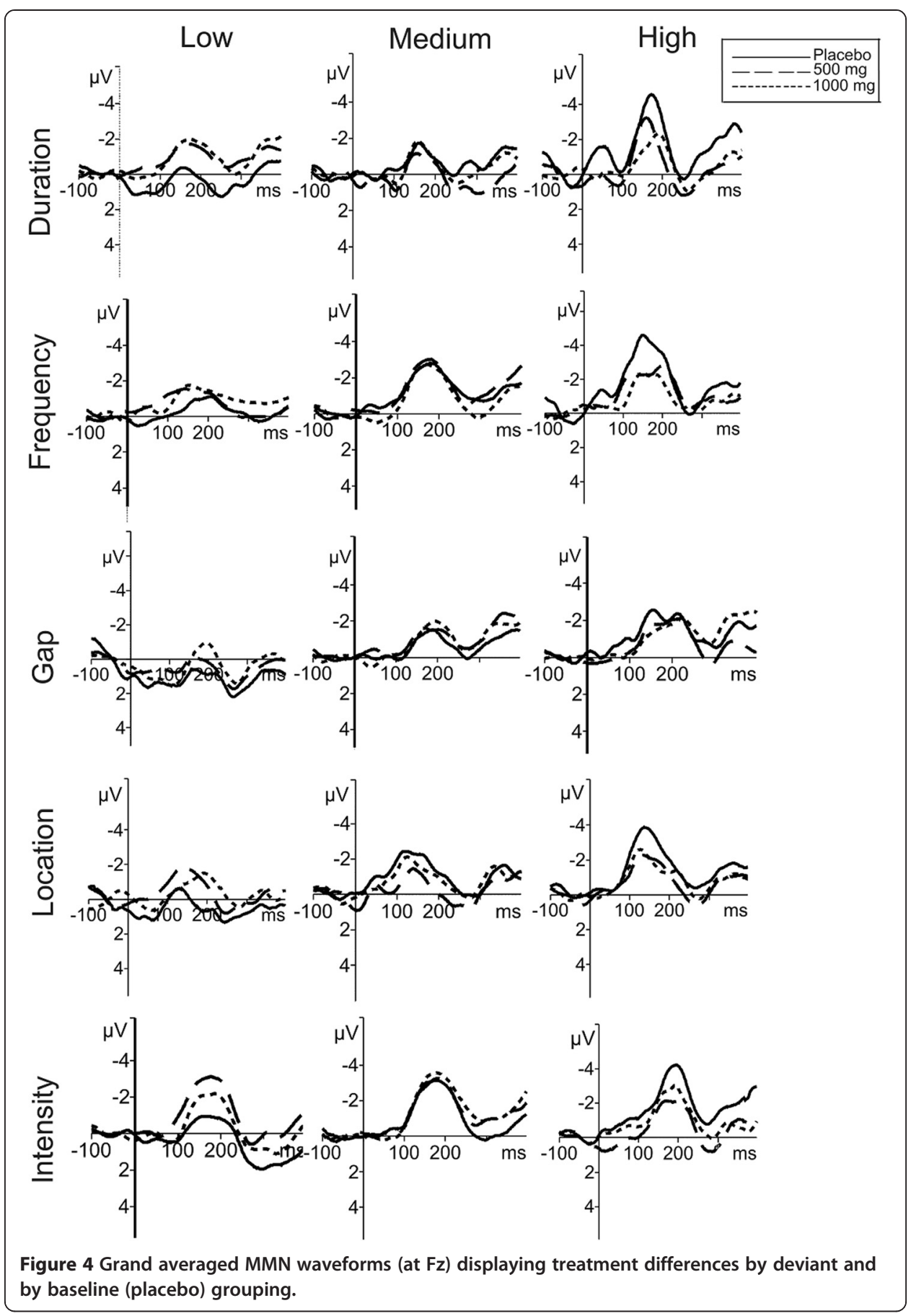

comparisons in the low baseline amplitude group showed the $500 \mathrm{mg}$ dose produced significantly larger MMNs than placebo $(p<0.01)$ and a similar, non-significant trend $(p<0.06)$ was shown with the $1000 \mathrm{mg}$ dose compared to placebo. The medium baseline group failed to exhibit any significant treatment effects but in the high baseline amplitude group MMN was attenuated (vs. placebo) with both $500 \mathrm{mg}(p<0.01)$ and $1000 \mathrm{mg}$ doses $(p<0.006)$.

Post-hoc comparisons showed groups to be significantly different from each other during placebo $(p<0.01)$ but not during the $500 \mathrm{mg}$ or $1000 \mathrm{mg}$ treatment sessions. 
MMN latency was not affected by treatment.

\section{Location MMN}

No treatment effect was found with group-wise analysis but a significant site effect was shown $[\mathrm{F}(2,42)=9.95, p<0.001]$, with amplitudes at Fz $>$ F4 $>$ F3 $(p<0.05)$.

The location MMN amplitudes were significantly altered by group $[\mathrm{F}(2,21)=7.60$, $p<0.01]$ and group $\mathrm{x}$ treatment interaction effects $[\mathrm{F}(4,36)=4.56, p<0.05]$. As observed in the low baseline amplitude group (Figure 4), treatment comparisons showed significant (vs. placebo) MMN amplitude increases with the $500 \mathrm{mg}$ dose $(p<0.05)$ and a similar but non-significant trend for MMN amplitude increases with the $1000 \mathrm{mg}$ dose $(p<0.08)$. CDP-choline exerted opposite effects in the medium and high baseline amplitude groups, with the $500 \mathrm{mg}$ reducing MMN compared to placebo $(p<0.05)$.

Group amplitudes were significantly different from each other during placebo treatment $(p<0.05)$ but not during CDP-choline treatment.

MMN latency analysis did not yield any significant main or interaction effects.

\section{Standard N1}

CDP-choline did not exert any significant effects on NI amplitude or latency.

\section{Additional analyses}

For the mixed ANOVAs conducted with subgroups formed with the $500 \mathrm{mg}$ session data and the $1000 \mathrm{mg}$ session data, significant group differences, as shown in the primary analysis, were observed for the different deviants but no significant treatment or group $\mathrm{x}$ treatment interactions were found.

\section{Adverse symptoms}

There were no serious adverse events associated with CDP-choline and no adverse events led to discontinuation by any of the participants. Analysis did not yield any significant treatment differences in self-reported adverse reactions.

\section{Vitals}

No significant differences were observed between placebo and CDP-choline doses with respect to heart rate or blood pressure measures.

\section{Discussion}

There were no significant whole group effects with CDP-choline but exploratory analysis showed individual differences in MMN response to the acute choline agonist challenge. Our findings with CDP-choline underscore previous reports of individual variability in sensory and cognitive response to nicotine and they extend these observations to the modulating effects of a choline supplement on auditory deviance detection, a preattentive sensory process which is commonly impaired in SZ. Depending on treatment dose, initial amplitude, and deviant type, deviance detection was shown to be enhanced, suppressed or insensitive to modulations of choline, which among its other properties, exerts agonist actions at $\alpha 7$ receptors. These findings add some support to the use of a "test dose" design in healthy surrogates, aided by specific biomarkers predicting and assessing 
an individual's drug sensitivity, for early detection of pro-cognitive effects of nicotinic agents for SZ cognition (Chou et al. 2012; Koychev et al. 2012).

Improvement in acoustic change detection with CDP-choline, in the absence of changes in obligatory sensory registration indexed by the NI ERP, was shown in individuals with relatively diminished neural response (MMN) to auditory deviants, while in those with optimal or supraoptimal responses, a reduction in change detection was evidenced with this acute $\alpha 7$ agonist treatment. In general, the findings parallel our earlier report of the dual actions of the broad spectrum nAChR agonist, nicotine, on MMN in groups of healthy surrogates exhibiting relatively compromised and efficient deviance detection (Knott et al. 2014). Increases in auditory change detection in individuals with diminished MMNs are of particular importance for SZ. Additionally, as these effects were shown in nonsmokers, the gains with CDP-choline reflect a true enhancement of a suboptimal sensory level process and are not simply reflecting a "normalization" or "remediation" of a sensory deficiency that may accompany the more general disturbance of cognitive neural networks seen during smoking/nicotine withdrawal in chronic smokers (Beaver et al. 2011; Cole et al. 2010).

The observation that both the augmenting and suppressing effects of CDP-choline on auditory change detection in the biomarker-defined subgroups were deviant dependent generally mirrors the baseline-dependent effects of nicotine reported in neuropsychiatric disorders, with those exhibiting the most impaired cognition in select domains evidencing the greatest improvement with nicotine (Morisano et al. 2013; Newhouse et al. 2004; Perkins 1999). Although non-significant dose-related trend effects were observed with some deviants (gap, intensity), CDP-choline in general was able to both increase (in low amplitude individuals) and decrease MMN (in high amplitude individuals) elicited by duration, intensity and location deviants. The MMN elicited by the frequency deviant was only attenuated, and not increased by CDP-choline, and this was shown in the high amplitude group. Gap-deviant MMN was not affected by the choline supplement, an effect which may in part be related to measurement variability as the MMN in the low amplitude group was relatively undetectable in the placebo and drug conditions.

The number, location, and roles of cortical MMN generators remains unresolved (Tata and Ward 2005) but neuroimaging evidence to date has implicated a temporofrontal network, with MMN and functional magnetic resonance imaging (fMRI) BOLD responses elicited by changes in regularity of different elemental auditory features being generated in separate loci of the superior temporal gyrus (Alho et al. 2013; Näätänen et al. 2011). The two distinct processes thought to be involved in auditory change detection, including a "sensory" mechanism (detects a deviant sound on the basis of differential refractoriness of neural populations sensitive to the standard and deviant sounds) and a "cognitive" mechanism (reveals deviance by comparing incoming auditory information with a template derived by previous input), also seem to be anatomically separate, with the former involving primary auditory areas, while the latter involves secondary auditory areas (Szycik et al. 2013). Differential sensitivity of auditory deviants to CDP-choline may reflect the variable distribution of neuronal $\alpha 7 \mathrm{nAChRs}$, which are heavily expressed in the primary auditory cortex and are integral to its structural and functional development (Ji and Suga 2008; Soto et al. 2006). In similar stratified subgroups, the deviance-dependent nicotine effects on MMN were shown to be slightly 
different in that the dual nicotine responses of MMN amplitude enhancement and suppression were not apparent with the same deviant type (i.e., nicotine either increased or decreased detection of specific auditory deviants), possibly reflecting regional differences in the number of non- $\alpha 7$ nicotinic receptors.

Although directly enhancing signal processing in primary sensory regions (Sarter and Bruno 1997), the diffuse cholinergic input system extends to the frontal cortex where it can trigger complex patterns of recruitment of cholinergic modules that project to sensory and sensory-associated cortical regions to enhance the detection and processing of stimuli of a particular modality (Gatmayo et al. 2003; Nelson et al. 2005). Nicotinic receptor stimulation modulates the release of multiple neurotransmitters, and enhances tone-evoked physiological responsivity in the auditory cortex via activation of NMDA receptor-mediated glutamatergic neurotransmission (Flores-Hernandez et al. 2009; Konradsson-Geuken et al. 2009; Levy and Aoki 2002; Liang et al. 2008; Metherate and Hsieh 2003; Metherate 2004; Yang et al. 2013). nAChRs are abundantly expressed in the prefrontal cortex (PFC) and play a key role in the regulation of complex cognitive processes (Wallace and Bertrand 2013b). Studies of MMN source localization point to a role for the frontal cortex, where $\alpha 7$ subunit receptors are found to be highly prominent in the postsynaptic density of glutamatergic synapses and are thought to provide the depolarization necessary for NMDA receptor neurotransmission (Yang et al. 2013). The ability of CDP-choline to modulate MMN in a manner that varies between individuals and deviant types may result from the coordinated interplay of $\alpha 7 \mathrm{nAChR}$ modulated NMDA sensory and higher cortical circuits, with each region varying inter-individually both in its participation in feature specific auditory change detection and its regulation by $\alpha 7$-nicotinic and glutamatergic signaling.

Dose differences emerged with CDP-choline, with MMN being affected most often with the lower $(500 \mathrm{mg}$ ) dose. Depending on the feature change, significant alterations in MMN seen with $500 \mathrm{mg}$ were sometimes observed with the $1000 \mathrm{mg}$ dose (durationand intensity-deviant $\mathrm{MMN}$ ), with the direction and degree of MMN change being similar across doses. Depending on the individual's amplitude, the same dose was able to increase and decrease neural responses to auditory deviants, CDP-choline generally acting to increase MMN in the low amplitude group while decreasing MMN in the higher amplitude group. Observed across the neuroimaging literature, the pattern of neural response induced by cholinergic modulation often resembles an inverted U-shaped function that depends upon the level of regional activation prior to drug challenge (Bentley et al. 2011). Hence, enhanced regional activity is most readily observed with pro-cholinergic drugs when such activity is relatively low under placebo, but decreased activity is seen when regional activation is high to begin with (e.g. Thiel et al. 2005). A similar type of inverted-U response is seen when comparing subject types, with pro-cholinergic drugs normalizing task/stimulus-evoked activations in individuals who, because of aging-, disease- or genetic-related factors, exhibit abnormally low or high activation, while in individuals with normal activation patterns studies show either no modulation or a reverse pattern of modulation in the same region and with the same task/stimulus paradigm (Bentley et al. 2011).

MMN increases with CDP-choline were most frequently observed with the low dose. Pro-cognitive effects of low and ultra-low doses of $\alpha 7$ agonists have been reported in 
numerous preclinical studies. Although the underlying neural mechanisms are still unclear, these low concentration agonists are described as 'co-agonists' as they have been shown to facilitate receptor activation and enhance the acetylcholine-evoked current without provoking receptor desensitization (Castner et al. 2011; Prickaerts et al. 2012; Wallace and Bertrand 2013a). As microdialysis studies have shown that $\alpha 7$ receptor agonists can directly increase glutamate (Gioanni et al. 1999) and dopamine levels in the prefrontal cortex (Livingstone et al. 2009; Sydserff et al. 2009), improved deviance detection indexed by frontal MMN increases with low dose CDP-choline may be achieved through multiple mechanisms.

Possibly related to individual differences in the number and sensitivity of $\alpha 7 \mathrm{nAChRs}$, diminished auditory change detection characterizing the low baseline amplitude group may be due to a relatively hypo-cholinergic state within sensory (auditory) cortex, while efficient detection of auditory change may reflect an optimal cholinergic tone. Consequently, the lower tonic cholinergic activity and decreased stimulus discriminability in the low baseline group allows for a greater dynamic range of response secondary to pro-cholinergic stimulation with CDP-choline, resulting in increased MMNs. By contrast, $\alpha 7$ agonist stimulation with CDP-choline in the high amplitude group may have pushed these participants towards a hyper-cholinergic state relative to what they are accustomed to, and while this enhances sensory cortex activation, concomitantly it results in reductions in selectivity to stimulus features and attributes (Bentley et al. 2011; Kuo et al. 2009; Zinke et al. 2006). Meta-analyses of imaging studies using magnetic resonance spectroscopy to quantify neurometabolites have shown reduced hippocampal choline (expressed as choline/creatine ratio) levels in SZ (Kraguljac et al. 2012) and it is possible that variability in endogenous brain choline may underly individual differences in normal deviance processing. Also of potential relevance to these findings of individual differences in response to CDP-choline is the choline uptake transporter (CHT), which imports choline from extracellular space to presynaptic terminals for use in normal acetylcholine synthesis/cholinergic transmission (Sarter and Parikh 2005). As CHT capacity has been associated with variability in cognitive functioning (Sarter and Parikh 2009), and as human CHT gene polymorphisms have been associated with individual differences in cortico-limbic activation (Neumann et al. 2006) and attentional processing (Berry et al. 2014), genetic differences in CHT capacity may underly some of the inter-individual variability in acoustic change detection response to CDP-choline.

\section{Limitations}

Our findings are preliminary and are in need of replication with larger samples. These data can be considered an incremental advancement in the current state of knowledge on choline agonism - sensory processing relationships with caveats of: 1) lack of real plasmabased biomarkers of endogenous choline availability; 2) no effort to control for covariates affecting choline activity or MMN, and 3) obviously, no SZ patients were studied. Although the recruitment of healthy volunteers can be considered a strength in that it reduced the potential confounding effects associated with clinical trials in patients (e.g. medication, disease chronicity), acute CDP-choline test-dose challenge studies are required in medicated patients prior to full phase II trials. Nonsmokers were targeted to ensure that any benefits gained with CDP-choline could not be attributed simply to a 
reversal of withdrawal-reduced cognitive impairment, which may play a role in smokers tested with nicotinic agents. Although nonsmoking patients are frequently used in early phase trials (e.g. Koike et al. 2005; Olincy et al. 2006), SZ smokers and nonsmokers have differed in their response to nicotine and $\alpha 7$ agonists (Lieberman et al. 2013) and comparison of their acute response to CDP-choline would inform future investigations. The dose levels were limited and may have included lower $(250 \mathrm{mg}$ ) and higher $(2000 \mathrm{mg})$ doses for a more complete dose-response profile, and future studies might repeat dosing in closely spaced sessions to examine issues related to receptor desensitization. Collection of choline plasma levels would also be useful in data interpretation. Our subgroups were based on placebo data, which was also included in the statistical analyses. It is possible that a 'regression to the mean' effect (arising from the fact that [low] deviance detection could only improve, and ceiling [high] deviance detection only deteriorate) may have contributed to the study findings, but the extent of this contribution is unclear and several factors do not convincingly support a strong role in that: a) with counterbalancing (see Analysis section), placebo was relatively equally distributed across the three sessions, thus substantially attenuating a regression to the mean effect; $b$ ) regression to the mean effects would be expected to be consistently shown with all deviant types and both doses but this was not the case and c) our additional set of mixed ANOVAs using the low or moderate dose session data to segment our groups did not result in any group $\mathrm{x}$ treatment interactions. From this analysis we can tentatively conclude that CDP-choline effects in our placebo-based MMN subgroups do not reflect a significant regression to the mean influence. However, reducing regression to the mean influences in future studies can be accomplished by selecting MMN subgroups from a larger sample, or study participants could undergo an additional 'pre-selective' session, the data from which would be used to stratify participants into subgroups but not for statistical analysis. MMN recordings were not taken from mastoid sites, which would have allowed for a more specific interpretation of CDP-choline effects on sensory processing at sites more proximal to the auditory cortex. Given the contribution of sensory level processing to higher order mental operations (Javitt 2000), neuropsychological testing accompanying the ERPs would help us to understand the cognitive implications of choline modulated sensory processing. Moreover, additional studies are required to assess whether sensory and/or cognitive mechanisms of auditory deviance detection are impacted by cholinergic stimulation. As nAChRs are found throughout midbrain and brainstem tracts of the auditory pathway (Habbicht and Vater 1996; Happe and Morley 1998; Happe and Morley 2004; Morley 2005), both regions being shown to display deviance detection properties (Escera et al. 2013), the use of early latency ERPs components ( $<100 \mathrm{~ms})$ may be important in mapping the extent to which $\alpha 7$ receptor modulation affects deviance processing along the auditory hierarchy.

\section{Conclusion}

Sensory and cognitive impairments are core features of SZ involving $\alpha 7$ nAChRs, which are considered potential therapeutic targets for new treatments. Using the MMN, one of the few biomarkers which can be reliably applied in translational research and drug development studies (Todd et al. 2013), acute $\alpha 7$ agonist treatment with the dietary supplement CDP-choline did not show any significant effects in our sample as a whole, but was shown to positively influence deviance detection in a surrogate subgroup 
displaying diminished deviance detection, while exerting detrimental effects in individuals exhibiting optimal deviance detection. Although these preliminary findings need replication and extension to other surrogate populations (e.g. schizotypal personality), the modulating low dose effects of CDP-choline on auditory change detection indexed with the translational biomarker MMN support further study of $\alpha 7$ receptor agonism as a potential sensory enhancing mechanism in patients with schizophrenia.

\section{Competing interests}

The authors declare that they have no competing interests.

\section{Authors' contributions}

Each of the authors participated in this research by contributing to the conception and design of the project (VK), performance of the experiment $(\mathrm{VI}, \mathrm{JC}, \mathrm{DS}, \mathrm{SD}, \mathrm{SS}, \mathrm{MS}, \mathrm{EB})$, event-related potential analysis (DI), and interpretation, writing and editing (VK, DI, Vl, AL). No technical writers, language editors, and/or writing agencies were employed in preparing the manuscript. All authors read and approved the final manuscript.

\section{Acknowledgements}

This work was supported in part by grants from the Natural Sciences and Engineering Research Council of Canada (NSERC) to VK, and from the University of Ottawa Medical Research Fund (UMRF) to VK and AL.

\footnotetext{
Author details

${ }^{1}$ University of Ottawa institute of Mental Health Research, Royal Ottawa Mental Health Care Centre, 1145 Carling Avenue, Ottawa, Ontario K1Z 7 K4, Canada. ${ }^{2}$ School of Psychology, University of Ottawa, Ottawa, ON, Canada. ${ }^{3}$ Department of Cellular and Molecular Medicine, University of Ottawa, Ottawa, ON, Canada. ${ }^{4}$ Department of Psychiatry, University of Ottawa, Ottawa, ON, Canada.
}

Received: 14 August 2014 Revised: 15 August 2014 Accepted: 4 November 2014

Published online: 06 May 2015

\section{References}

Agut J, Font E, Sacristan A, Ortiz J (1983) Bioavailability of methyl-14C CDP-choline by oral route. Arzneimitteforschong 33:1045-1047

Albuquerque E, Pereira E, Bruga M, Alkondon M (1998) Contribution of nicotinic receptors to the function of synapses in the central nervous system: the action of choline as a selective agonist of alpha 7 receptors. J Physiol 92:309-316

Alho K, Rinne T, Herron T, Woods P (2013) Stimulus-dependent activations and attentional-related modulations on the auditory cortex: A met-analysis of fMRI studies. Hear Res 307:29-41

Alkondon M, Pereira E, Eisenberg H, Albuquerque E (1999) Choline and selective antagonists identify two subtypes of nicotinic acetylcholine receptors that modulate GABA release from CAl interneurons in rat hippocampal slices. J Neurosci 19:2693-2705

Alvarez-Sabin J, Roman G (2011) Citicoline in vascular cognitive impairment and vascular dementia after stroke. Stroke 42:S40-\$43

Baldeweg T, Wong D, Stephan K (2006) Nicotinic modulation of human auditory sensory memory: evidence from mismatch negativity potentials. Int J Psychophysiol 59:49-58

Barnett A, van der Pols J, Dobson A (2005) Regression to the mean: What it is and how to deal with it. Int J Epidemiol $34: 215-220$

Bazana P, Stelmack R (2002) Intelligence and information processing during an auditory discrimination task with backward masking: an event-related potential analysis. J Pers Soc Psychol 83:998-1008

Beaver J, Long C, Cole D, Durcan M, Bannon L, Mishara R, Matthews P (2011) The effects of nicotine replacement on cognitive brain activity during smoking withdrawal studies with simultaneous fMRI/EEG. Neuropsychopharmacology 36:1792-1800

Belger A, Yucel G, Donkers F (2012) In search of psychosis biomarkers in high-risk populations: Is the mismatch negativity the one we have been waiting for? Biol Psychiatry 71:94-95

Bencherif M, Stachowlak M, Kucinski A, Lippiello P (2012) Alpha1 nicotinic cholinergic neuromodulation may reconcile multiple neurotransmitter hypotheses of schizophrenia. Med Hypoth 78:594-600

Bentley P, Driver J, Dolan R (2011) Cholinergic modulation of cognition: Insights from human pharmacological functional neuroimaging. Prog Neurobiol 94:360-388

Berry A, Demeter E, Sabhapathy S, English B, Blakely R, Sarter M, Lustig C (2014) Disposed to distraction: Genetic variation in the cholinergic system influences distractibility but not time-on-task effects. J Cog Neurosci 26:1981-1991

Blusztajn J (1998) Choline, a vital amine. Science 281:794-795

Buchanan R, Freedman R, Javitt D, Abi-Dargham A, Lieberman J (2007) Recent advances in the development of novel pharmacological agents for the treatment of cognitive impairments in schizophrenia. Schizophr Bull 33:1120-1130

Butler P, Chen Y, Ford J, Geyer M, Silverstein S, Green M (2012) Perceptual measurement in schizophrenia: Promising electrophysiology and neuroimaging paradigms from CNTRICS. Schizophr Bull 38:81-91

Castner S, Smagin G, Piser T, Wang Y, Smith J, Christian E, Mrzljak L, Williams G (2011) Immediate and sustained improvement in working memory after selective stimulation of a7 nicotinic acetylcholine receptors. Biol Psychiatry 69:12-18 
Chou H-H, Twamley E, Swerdlow N (2012) Towards medication-enhancement of cognitive interventions in schizophrenia. Hand Exp Pharmacol 213:81-111

Cole D, Beckmann C, Long C, Matthews P, Durcan M, Beaver J (2010) Nicotine replacement in abstinent smokers improves cognitive withdrawal symptoms with modulation of resting brain network dynamics. Neuroimage 52:590-599

Conant R, Schauss A (2004) Therapeutic applications of citicoline for stroke and cognitive dysfunction in the elderly: A review of the literature. Alt Med Rev 9:17-31

Corriveau J, Glenn M (2012) Postnatal choline levels mediate cognitive deficits in a rat model of schizophrenia. Pharm Biochem Behav 103:60-68

Court J, Spurden D, Lloyd S (1999) Neuronal nicotinic receptors in dementia with Lewy bodies and schizophrenia: alpha-bungarotoxin and nicotine binding on the thalamus. J Neurochem 73:1590-1597

Cropsey K, Eldridge G, Weiver M, Villalobos G, Stitzer M (2006) Expired carbon monoxide levels in self-reported smokers and nonsmokers in prison. Nicotine Tob Res 8:653-659

D'Souza M, Markou A (2012) Schizophrenia and tobacco smoking comorbidity: nAChR agonists in the treatment of schizophrenia-associated cognitive deficits. Neuropharma Col 62:1564-1573

Davalos A, Alvarez-Sabin J, Castillo J, Diez-Tejedor E, Ferro J, Martinez-Villa E, Serenna J, Sequira T, Cruz V, Musjuan J, Cobo E, Secades J (2012) Citicoline in the treatment of acute ischaemic stroke: an international, randomized, multicentre, placebo-controlled study (ICTUS trial). Lancet 380:349-357

Deutsch S, Schwartz B, Schooler N, Brown C, Rosse R, Rosse S (2013) Targeting alpha-7 nicotinic neurotransmission in schizophrenia: A novel agonist strategy. Schizophr Res 148:138-144

Dickerson F, Stallings C, Origoni A, Vaughan C, Khushalani S, Schroeder J, Yolken R (2013) Cigarette smoking among persons with schizophrenia or bipolar disorder in routine-clinical settings. 1999-2011. Psychiatr Serv 64:44-50

Dos Santos C, Granon S (2012) Prefrontal neuromodulation by nicotinic receptors for cognitive processes. Psychopharmacol 22:1-18

Dulude L, Labelle A, Knott V (2010) Acute nicotine-alteration of sensory memory impairment in smokers with schizophrenia. J Clin Psychopharmacol 30:541-548

Dunbar G, Boeijinga H, Demazieres A, Cisterni C, Kuchibhatla R, Wesnes K, Luthringer R (2007) Effects of TC-1734 (AZD3480), a selective neuronal nicotinic receptor agonist, on cognitive performance and the EEG of young healthy male volunteers. Psychopharmacol 191:919-929

Escera C, Leung S, Grimm S (2013) Deviance detection based on regularity encoding along the auditory hierarchy: Electrophysiological evidence in humans. Brain Topogr. Epub ahead of print.

Fayuk D, Yakel J (2004) Regulation of nicotinic acetylcholine receptor channel function by acetylcholinesterase inhibitors in rat hippocampal CAl interneurons. Mol Pharmacol 66:658-666

Fioravanti M, Buckley A (2006) Citicoline (Cognizin) in the treatment of cognitive impairment. Clin Int Aging 1:247-251

Fisher D, Scott T, Shah D, Prise S, Thompson M, Knott V (2010) Light up and see: Enhancement of the visual mismatch negativity (VMMN) by nicotine. Brain Res 1313:162-171

Fisher D, Grant B, Smith D, Borracci G, Labelle A, Knott V (2012) Nicotine and the hallucinating brain: Affects on mismatch negativity (MMN) in schizophrenia. Psychiatry Res 196:181-187

Fishman Y (2013) The mechanisms and meaning of the mismatch negativity. Brain Topogr 27:500-526

Flores-Hernandez J, Salgado H, De la Rossa V, Avila-Ruiz T, Tarres-Ramirez O, Lopez-Lopez G, Asori M (2009) Cholinergic direct inhibition of M-methyl-D-aspartate receptor-mediated currents in the rat neurocortex. Synapse 63:308-318

Freedman R (2014) a7-nicotinic acetylcholine receptor agonists for cognitive enhancement in schizophrenia. Annu Rev Med 65:1-8

Freedman R, Hall M, Adler L, Leonard S (1995) Evidence in postmortem brain tissue for decreased numbers of hippocampal nicotinic receptors in schizophrenia. Biol Psychiatry 38:22-33

Freedman R, Coon H, Myles-Worsley M, Orr-Urteger A, Olincy A, Davis A, Polymeropoulos M, Holik J, Hopkins J, Hoff M, Rosenthal J, Waldo M, Reinherr R, Wender P, Yaw J, Young D, Brese C, Adams C, Patterson D, Adler L, Kruglyak L, Leonard S, Byerley W (1997) Linkage of a neurophysiological deficit in schizophrenia to a chromosome 15 locus. Proc Natl Acad Sci U S A 94:507-592

Freedman R, Olincy A, Buchanan R, Harris J, Gold J, Johnson L, Allensworth D, Guzman-Bonilla A, Clement B, Ball M, Kutnick J, Pender V, Martin L, Stevens K, Wagner B, Zerbe G, Soti F, Kem W (2008) Initial phase 2 trial of a nicotinic agonist in schizophrenia. Am J Psychiatry 165:1040-1047

Garcia-Cobos R, Frank-Garcia A, Gutirrez-Fernandez M, Diez-Tejedor F (2010) Citicoline, use in cognitive decline: vascular and degenerative. J Neurol Sci 299:188-192

Gatmayo L, Nunez A, Zaborszky L (2003) Electrophysiological evidence for the existence of posterior cortical-prefrontalbasal forebrain circuitry on modulating sensory responses in visual and somatosensory rat cortical areas. Neurosci 119:597-609

Geerts H (2012) a7 nicotinic receptor modulators for cognitive deficits in schizophrenia and Alzheimer's disease. Expert Opin Investig 21:59-65

Gilbert D, Gilbert B (1995) Personality psychopathology, and nicotine response as mediations of the genetics of smoking. Behav Genet 2f:133-147

Gioanni Y, Rougeot C, Clarke P, Lepouse C, Thierny A, Vidal C (1999) Nicotinic receptors in the rat prefrontal cortex: increases in glutamate release and facilitation of mediodorsal thalamo-cortical transmission. Eur J Neurosci 11:18-30

Gold J (2004) Cognitive deficits as treatment targets in schizophrenia. Schizophr Res 72:21-28

Gottesman L, Gould T (2003) The endophenotype concept in psychiatry: etymology and strategic intentions. Am J Psychiatry 160:636-645

Gratton G, Coles M, Douchin E (1983) A new method for off-line removal of ocular artifact. Electroencephalogr Clin Neurophysiology 55:468-484

Green M (2007) Stimulating the development of drug treatments to improve cognition in schizophrenia. Ann Rev Clin Psychol 3:159-180

Green M, Butler P, Chen Y, Geyer M, Silverstein S, Wynn J, Yoon J, Zemon V (2009) Perception measurement in clinical trials of schizophrenia: Promising paradigms from CNTRICS. Schizophr Bull 35:163-181 
Guan Z, Zhan X, Blennow K, Nordberg A (1999) Decreased protein level of nicotinic receptor [alpha] 7 subunit in the frontal cortex from schizophrenia brain. Neuroreport 10:1779-1782

Habbicht H, Vater M (1996) A microiontophoretic study of acetylcholine effects in the inferior colliculos of horeshoe bats: implications for a modulatory role. Brain Res 724:169-179

Hahn B, Shoaib M, Stolerman I (2002) Nicotine-induced enhancement of attention in the five-choice serial reaction time task: the influence of task demands. Psyhcopharmacol 162:129-137

Happe H, Morley B (1998) Nicotinic acetylcholine receptors in rate colchear nucleus: [125]-alpha-bungarotoxin receptor autoradiography and in situ hybridization of alpha 7 nAChR subunit mRNA. J Comp Neural 397:163-180

Happe H, Morley B (2004) Distribution and postnatal development of alpha7 nicotinic acetylcholine receptors in the rodent lower auditory brainstem. Brain Res Div Brain Res 153:29-37

Harkrider A, Hedrick M (2005) Acute effect of nicotine on auditory gating in smokers and non-smokers. Hear Res 202:114-128

Heishman S, Taylor R, Henningfield J (1994) Nicotine and smoking: a review of effects on human performance. Exp Clin Psychopharmacol 2:345-395

Heishman S, Kleykamp B, Singleton E (2010) Meta-analysis of the acute effects of nicotine and smoking on human performance. Psychopharmacol 210:453-469

Hilt D, Meltzer H, Gawry M, Ward S, Dgetluck N, Bhuvaneswaran C (2011) EVP-6124, and alpha-7 nicotinic partial agonist, produces positive effects on cognition, clinical function, and negative symptoms in patients with chronic schizophrenia on stable antipsychotic therapy. Abstract accepted in presentation of the 50th Annual Meeting of the American College of Neuropsychopharmacology: Waikoloa, Hawaii, 4-8 December. www.acnp.org/ annualmeeting/programbooks.aspx.

Horton J, Millar A, Labelle A, Knott V (2011) MMN responsivity to manipulations of frequency and duration deviants in chronic, clozapine-treated schizophrenia patients. Schizophr Res 126:202-218

Hurst R, Rollema H, Bertrand D (2012) Nicotinic acetylcholine receptors: From basic science to therapeutics. Pharmacol Ther 137:22-54

Ichikawa J, Dai J, O'Laughlin I, Fowler W, Meltzer H (2002) Atypical but not typical antipsychotic drugs increase cortical acetylcholine release without an effect in the nucleus accumbens or striatum. Neuropsychopharmacol 26:325-339

Inami R, Kirino E, Inoue R, Suzuki T, Arai H (2007) Nicotine effects on mismatch negativity in nonsmoking schizophrenic patients. Neuropsychobiol 56:64-72

Javitt D (2000) Intracortical mechanisms of mismatch negativity dysfunction in schizophrenia. Audiol Neuro Tol 5:207-215

Javitt D (2009) When doors of perception close: bottom-up models of disrupted cognition in schizophrenia. Ann Rev Clin Psychol 5:249-275

Javitt D, Steinschneider M, Schroeder C, Arezzo J (1996) Role of cortical N-methyl-D-aspartate in auditory sensory memory and mismatch negativity generation: implications for schizophrenia. Proc Natl Acad Sci U S A 93:11962-11967

Javitt D, Spencer K, Thaker G, Winterer G, Hajos M (2008) Neurophysiological biomarkers for drug development in schizophrenia. Nat Rev Drug Discov 7:68-83

Ji W, Suga N (2008) Tone-specific and nonspecific plasticity of the auditory cortex elicited by pseudoconditioning: rule of acetylcholine receptors and the somatosensory cortex. J Neurophysiol 100:1384-1396

Kiang M, Light G, Prugh J, Coulson S, Bralb D, Kutas M (2007) Cognitive, neurophysiological and functional correlates of proverb interpretation abnormalities in schizophrenia. J Int Neuropsychol Soc 13:653-663

Knott V, Scherling C, Blais C, Camarda J, Fisher D, Millar D, McIntosh J (2006) Acute nicotine fails to alter event-related potential or behavioural performance indices of auditory distraction in cigarette smokers. Nic and Tob Res 8:263-273

Knott V, Bolton K, Heenan A, Shah D, Fisher D, Villeneuve C (2009) Effects of acute nicotine on event-related potential and performance indices of auditory distraction in nonsmokers. Nic and Tob Res 11:519-530

Knott V, Fisher D, Millar A (2010) Differential effects of nicotine on P50 amplitude, its gating and their neural sources in low and high suppressions. Neurosci 170:816-826

Knott V, Heenan A, Shah D, Bolton K, Fisher D, Villeneuve C (2011) Electrophysiological evidence of nicotine's distractorfiltering properties in non-smokers. J Psychopharmacol 25:239-248

Knott V, Shah D, Millar A, McIntosh J, Fisher D, Blais C, llivitsky V (2012) Nicotine, auditory sensory memory, and sustained attention in a human ketamine model of schizophrenia: Moderating influence of an hallucinatory trait. Front Pharmacol 3:172

Knott V, de la Salle S, Smith D, Phillips T, Dort H, Choueiry J, Impey D (2013) Baseline dependency of nicotine's sensory gating actions: similarities and differences in low, medium and high P50 suppressors. J Psychopharmacol 27:790-800

Knott V, Impey D, Philippe J, Smith D, Choueiry J, de la Salle S, Dort H (2014) Modulation of auditory deviance detection by acute nicotine is basleine- and deviant-dependent in healthy nonsmokers: A mismatch negativity study. Hum Psychopharmacol 29:446-458

Koike K, Hashimoto K, Takai N, Shimizo T, Komatsu N, Watanabe H, Nakazato M, Okamura N, Stevens K, Freedman R, Tyo M (2005) Topisetron improves deficits in auditory P50 suppression in schizophrenia. Schizophr Res 76:67-72

Konradsson-Geuken A, Gash C, Alexander K, Pomerleau F, Huetti P, Gerhardt G, Bruno J (2009) Second-by-second analysis of alpha 7 nicotinic receptor regulation of glutamate release in the prefrontal cortex of awake rats. Synapse 63:1069-1082

Koychev I, McMullen K, Lees J, Dadhiwala R, Grayson L, Perry C, Schmechtig A, Walters J, Craig K, Dawson G, Dovrish C, Ettinger U, Wilkinson L, Williams S, Deakin J, Barkus E (2012) A validation of cognitive biomarkers for the early identification of cognitive enhancing agents in schizotypy: A three-center double-blind placebo-controlled study. Eur Neuropsychopharmacol 22:469-481

Kraguljac N, Reid M, White D, Jones R, den Hollander J, Lowman D, Lahti A (2012) Neurometabolites in schizophrenia and bipolar disorder - A systematic review and meta-analysis. Psychiatry Res 203:111-125 
Kucinski A, Stachowiak M, Wersinger S, Lippiello P, Bencherif M (2011) Alpha 7 neuronal nicotinic receptors as targets for novel therapies to treat multiple domains of schizophrenia. Curr Pharm Biotechnol 12:437-448

Kumari V, Postma P (2005) Nicotine use in schizophrenia: the self medication hypotheses. Neurosci Biobehav Rev 29:1021-1034

Kuo M, Rasmusson D, Dringenberg H (2009) Input-selective potentiation and rebalancing of primary sensory cortex afferents by endogenous acetylcholine. Neurosci 113:430-441

Kupferschmidt D, Funk D, Erb S, Lo A (2010) Age-related effects of acute nicotine on behavioural and neuronal measures of anxiety. Behav Brain Res 213:289-292

Leach N, Nodal F, Cordery P, King A, Bajo V (2013) Cortical cholinergic input is required for normal auditory perception and experience-dependent plasticity in adult ferrets. J Neurosci 33:6059-6671

Lee S-H, Sung K, Lee K-S, Moon E, Kim C-G (2014) Mismatch negativity is a stronger indicator of functional outcomes than neurocognition or theory of mind in patients with schizophrenia. Prog Neuro-Psychopharmacol Biol Psychiatry 48:213-219

Leiser S, Bowlby M, Comery T, Dunlop J (2009) A cog in cognition: how the alpha 7 nicotinic acetylcholine receptor is geared towards improving cognitive deficits. Pharmacol Ther 122:302-311

Leonard S, Gault J, Hopkins J, Logel J, Vianzon R, Short M, Drebing C, Berger R, Venn D, Sirora V, Zerbe G, Olincy A, Ross R, Adler L, Freedman R (2002) Promoter variants in the alpha7 nicotinic acetylcholine receptor subunit gene are associated with an inhibitory deficit found in schizophrenia. Arch Gen Psychiatry 59:1085-1090

Levin E, McClernon F, Rezvani A (2006) Nicotinic effects on cognitive function: behavioural characterization, pharmacological specification, and anatomic localization. Psychopharmacol 184:523-539

Levy R, Aoki C (2002) a7 nicotinic acetylcholine receptors occur at postsynaptic densities of AMPA receptor-positiveand negative-excitatory synapses of rat sensory cortex. J Neurosci 22:5001-5015

Li M, Mead A, Bevins R (2009) Individual differences in response to nicotine: tracking changes from adolescence to adulthood. Acta Pharmacol Sin 30:868-878

Liang K, Poytress B, Weinberger M, Metherate R (2008) Nicotinic modulation of tone-evoked responses in auditory cortex reflects the strength of prior learning. Neurobiol Learn Mem 90:138-146

Lieberman J, Dunbar G, Segreti A, Girgis R, Seoane F, Beaver J, Duan N, Hosford D (2013) A randomized exploratory trial of an alpha-7 nicotinic receptor agonist (TC-5619) for cognitive impairment in schizophrenia. Neuropsychopharmacol 38:968-975

Light G, Braff D (2005) Mismatch negativity deficits are associated with poor functioning in schizophrenia patients. Arch Gen Psychiatry 62:127-136

Light G, Swerdlow M, Braff D (2007) Preattentive sensory processing as indexed by the MMN and P38 brain responses associated with cognitive and psychosocial functioning in healthy adults. J Cogn Neurosci 19:1624-1632

Light G, Swerdlow N, Rissling A, Radant A, Sugar C, Sprock J, Pela M, Braff D (2012) Characterization of neurophysiologic and neurocognitive biomarkers for use in genomic and clinical outcome studies of schizophrenia. PLoS One 7:e3934

Livingstone P, Srinivasan J, Kew J, Dawson L, Gotti C, Moretti M, Shoaib M, Wonnacott S (2009) Alpha7 and non-alpha7 nicotinic acetylcholine receptors modulate dopamine release in vitro and in vivo in the rat prefrontal cortex. Eur J Neurosci 29:539-550

Mansvelder H, Van Aerde K, Couey J, Brussaard A (2006) Nicotinic modulation of neuronal networks: from receptors to cognition. Psychopharmacol 184:292-305

Marder S, Fenton W (2004) Measurement and treatment research to improve cognition in schizophrenia: NIMH MATRICS initiative to support the development of agents for improving cognition in schizophrenia. Schizophr Res 72:5-9

Martin L, Davalos D, Kisley M (2009) Nicotine enhances automatic temporal processing as measured by the mismatch negativity waveform. Nic Tob Res 11:698-706

Mathalon D, Aha K, Perry E, Cho HS, Roach B, Blais R (2014) Effects of nicotine on the neurophysiological and behavioural effects of ketamine in humans. Fron Psychiatry 5:3

Matsubayashi J, Kawakubo Y, Suga M, Takei Y, Kumano S, Fukuda M, Itoh K, Yumoto M, Kasai K (2008) The influence of gender and personality traits on individual difference in auditory mismatch: A magnetoencephalographic (MMNm) study. Brain Res 1236:159-165

Maxwell M (1992) Family Interview for Genetic Studies (FIGS): Manual for FIGS. Clinical Neurogenetics Branch, Intramural Research Program. National Institute of Mental Health, Bethesda, MD

May $\mathrm{P}$, Tiitinin $\mathrm{H}$ (2010) Mismatch negativity (MMN), the deviance-elicited auditory deflection, explained. Psychophysiology 47:66-122

Meck W, Williams C (2003) Metabolic imprinting of choline by its availability during gestation: implication for memory and attentional processing across the lifespan. Neurosci Biobehav Rev 27:385-399

Metherate R (2004) Nicotinic acetylcholine receptors in sensory cortex. Learn Mem 11:50-59

Metherate R, Hsieh C (2003) Regulation of glutamate synapses by nicotinic acetylcholine receptors in auditory cortex. Neurobiol Learn Mem 80:285-290

Morisano D, Wing V, Sacco K, Arenovich T, George T (2013) Effects of tobacco smoking on neuropsychological function in schizophrenia in comparison to other psychiatric disorders and non-psychiatric controls. AMJ Addict 22:46-53

Morley B (2005) Nicotinic cholinergic intercellular communication: implications for the developing auditory system. Hear Res 206:74-88

Näätänen R, Kahkonen S (2008) Central auditory dysfunction in schizophrenia as revealed by the mismatch negativity (MMN) and its magnetic equivalent MMNm: a review. Int J Neuropsychopharmacol 12:125-135

Näätänen R, Pakarinen S, Rinne T, Takegata R (2004) The mismatch negativity (MMN): Towards the optimal paradigm. Clin Neurophysiol 115:140-144

Näätänen R, Kujala T, Winkler I (2011) Auditory processing that leads to conscious perception: a unique window to central auditory processing opened by the mismatch negativity and related responses. Psychophysiology 48:4-12

Näätänen R, Kujala T, Escera I, Baldeweg T, Kreesipuu K, Carlson S, Ponton C (2012) The mismatch negativity (MMN) unique window to disturbed central auditory processing in aging and different clinical conditions. Clin Neurophysiol 123:424-458 
Näätänen R, Sussman E, Salisbury D, Shafer V (2014) Mismatch negativity (MMN) as an index of cognitive dysfunction. Brain Topogr 27:451-466

Nagai T, Tada M, Kirihara K, Araki T, Jinde S, Kasai K (2013a) Mismatch negativity as a "translatable" brain marker toward early intervention for psychosis: a review. Front Psychiatry 4:115

Nagai T, Tada M, Kirihara K, Yahata N, Hashimoto R, Araki T, Kasai K (2013b) Auditory mismatch negativity and P3a in response to duration and frequency changes in the early stages of psychosis. Schizophre Res 150:547-554

Nelson C, Sarter M, Bruno J (2005) Preftonal cortical modulation of acetylcholine release in posterior parietal cortex. Neuroscience 132:347-359

Neumann S, Brown S, Ferrell R, Flory J, Manuck S, Hariri A (2006) Human choline transporter gene variation is associated with corticolimbic reactivity and autonomic-cholinergic function. Biol Psychiatry 60:1155-1162

Newhouse P, Potter A, Singh A (2004) Effects of nicotinic stimulation on cognitive performance. Curr Opin Pharmacol 4:36-46

Olincy A, Freedman R (2012) Nicotinic mechanisms in the treatment of psychotic disorders: a focus on the alpha7 nicotinic receptor. Handb Esp Pharmacol 213:211-232

Olincy A, Harris J, Johnson L, Pender V, Kongs S, Allensworth D, Ellis J, Zerbe G, Leonard S, Stevens K, Stevens J, Martin L, Adler L, Sote F, Kem W, Freedman R (2006) Proof-of-concept trial of an a7 nicotinic agonist in schizophrenia. Arch Gen Psychiatry 63:630-638

Perkins K (1995) Individual variability in response to nicotine. Behav Genet 25:119-132

Perkins K (1999) Baseline-dependency of nicotine affects: a review. Behav Pharmacol 10:595-615

Perkins K (2009) Sex differences in nicotine reinforcement and reward: influences on the persistence of tobacco smoking. Nebr Symp Motiv 55:143-169

Poltavski D, Petros T (2005) Effects of transdermal nicotine on prose memory and attention in smokers and nonsmokers. Physiol Behav 83:833-843

Preskorn S, Gawryl M, Dgetuck N, Palfreyman M, Bauer L, Hilt D (2014) Normalizing effects of EVP-6124, an alpha-7 nicotinic partial agonist, on event-related potentials and cognition: A proof of concept, randomized trial in patients with schizophrenia. J Psychitr Pract 20:12-24

Prickaerts J, van Goethen N, Chesworth R, Shapiro G, Boess F, Methfessel C, Reneenkens C, Flood D, Hilt D, Gawry M, Bertrand S, Bertrand D, Konig G (2012) EVP-6124, a novel and selective a7 nicotinic acetylcholine receptor partial agonists improve memory performance by improving the acetylcholine response of a7 nicotinic receptors. Neuropharmacol 62:1099-1110

Radek R, Kohlhaas K, Reuter L, Mohler E (2010) Treating the cognitive deficits of schizophrenia with alpha4beta2 neuronal nicotinic receptor agonists. Curr Pharm Res 16:309-322

Rasser P, Schall U, Todd J (2011) Gray matter deficits, mismatch negativity and outcomes in schizophrenia. Schizophr Bull 37:131-140

Raux G, Bonnet-Brilhault F, Louchart S, Houy E, Gantier R, Levillain D, Allio G, Haouzir S, Petit M, Martinez M, Frebourg T, Thibault F, Campion D (2002) The -2 bp deletion in exon 6 of the 'alpha 7-like' nicotinic receptor subunit gene is a risk factor for the P50 sensory gating deficit. Mol Psychiatry 7:1006-1011

Ross R, Hunter S, McCarthy L, Beuler J, Hutchison A, Wagner B, Leonard S, Sevens K, Freedman R (2013) Perinatal choline effects on neonatal pathophysiology related to later schizophrenia risk. Am J Psychiatry 170:240-298

Ruzzoli M, Pirulli C, Brignani D, Maioli C, Miniussi C (2012) Sensory memory during physiological aging indexed by mismatch negativity (MMN). Neurobiol Aging 33:e21-e30

Sabri M, Campbell K (2002) The effects of digital filtering on mismatch negativity in wakefulness and slow-wave sleep. $J$ Sleep Res 11:123-127

Salisbury D, Kuroki N, Kasai K, Shenton M, McCarley R (2007) Progressive and interrelated functional and structural evidence of post-onset brain reduction in schizophrenia. Arch Gen Psychiatry 64:521-529

Sarter M, Bruno J (1997) Cognitive functions of cortical acetylcholine: toward a unifying hypothesis. Brain Res Rev 23:28-46

Sarter M, Parikh V (2005) Cholinergic transporters, cholinergic transmission and cognition. Nature Rev 6:48-56

Sarter M, Parikh V, Howe W (2009) nAChR-agonist induced cognition enhancement: integration of cognitive and neuronal mechanisms. Biochem Pharacol 78:658-667

Saver J (2008) Citicoline: update on a promising and widely available agent for neuroprotection and neuroreport. Rev Neurol Dis 5:167-177

Secades J (2012) Probable role of citicoline in stroke rehabilitation: review of literature. Rev Neurol 54:173-179

Secades J, Frontera G (1995) CDP-choline: pharmacological and clinical review. Methods Find Exp Clin Pharmacol Suppl B: 1-54.

Soto G, Kopell M, Sen K (2006) Network architecture, receptive fields, and neuromodulation: computational and functional implications of cholinergic modulation in primary auditory cortex. J Neurophysiol 96:2972-2983

Stevens K, Adams C, Yonchek J, Hickel C, Danielson J, Kisley M (2008) Permanent improvement on deficient sensory inhibition in DBA/2 mice with increased perinatal choline. Psychopharmacol 198:413-420

Stevens K, Choo K, Stitzel J, Marks M, Adams C (2014) Long-term improvements in sensory inhibition with gestational choline supplementation linked to a7 nicotinic receptors through studies in Chrna7 null mutation mice. Brain Res 1552:23-33

Sumiyoshi T, Miyanishi T, Seo T, Higuchi Y (2013) Electrophysiological and neuropsychological predictors of conversion to schizophrenia in at-risk subjects. Front Behav Neurosci 7:148

Sydserff S, Sutton E, Song D, Quirk M, Maciag C, Li C, Jonah G, Gurley D, Gordon J, Christian E, Doherty J, Hudzik T, Johnson E, Mrzljak L, Piser T, Smagin G, Wang Y, Widzowski D, Smith J (2009) Selective alpha 7 nicotinic receptor activation by AZD0328 enhances cortical dopamine release and improves learning and attentional processes. Biochem Pharmacol 78:880-888

Szycik G, Stadler J, Brechmann A, Munte T (2013) Preattentive mechanisms of change detection in early auditory cortex: A 7 telsa FMRI study. Neurosci 253:100-109

Takahashi H, Rissling A, Pascual-Marqui R, Kirihara K, Pela M, Sprock J, Braff D, Light C (2013) Neural substrates of normal and impaired preattentive sensory discrimination in large cohorts of nonpsychiatric subjects and schizophrenia patients as indexed by MMN and P3a change detection responses. Neuroimage 66:594-603 
Tanahashi S, Yamamura S, Nakagawa M, Motomura E, Okada M (2012) Clozapine, but not haloperidol, enhances glial D-serine and L-glutamate release in rat prefrontal cortex and primary cultural astrocytes. Br J Pharmacol 165:1543-1555

Tata M, Ward L (2005) Early phase of spatial mismatch negativity is localized to a posterior "where" auditory pathway. Exp Brain Res 167:481-486

Thiel C, Zilles K, Fink G (2005) Nicotine modulates reorienting of visuospatial attention and neural activity in human parietal cortex. Neuropsychopharmacology 30:810-820

Tikhonravov D, Neuvonen T, Pertovaara A, Savioja K, Ruusuvirta T, Näätänen R, Carlson S (2008) Effects of an NMDA receptor antagonist MK-801 on an MMN-like response in anesthetized rats. Brain Res 1203:97-102

Todd J, Michie P, Schall U, Karayanidis F, Yabe H, Näätänen R (2008) Deviant matters: duration, frequency, and intensity deviants reveal different patterns of mismatch negativity reduction in early and late schizophrenia. Biol Psychiatry 63:58-64

Todd J, Harms L, Schall U, Michie P (2013) Mismatch negativity: translating the potential. Front Psychiatry 4:171

Turetsky B, Bilker W, Siegel S, Kohler C, Gur R (2009) Profile of auditory information processing deficits in schizophrenia. Psychiatry Res 165:27-37

Umbricht D, Schmid L, Koller R, Vollenweider F, Hill D, Javitt D (2000) Ketamine-induced deficits in auditory and visual context-dependent processing in healthy volunteers. Arch Gen Psychiatry 57:1139-1197

Umbricht D, Bates J, Lieberman J, Kune J, Javitt D (2006) Electrophysiological indices of automatic and controlled auditory information processing in first episode, recent onset and chronic schizophrenia. Biol Psychiatry 59:762-772

Umbricht D, Keefe R, Murray S, Lowe D, Porter R, Garibaldi G, Santarelli L (2014) A randomized, placebo-controlled study investigating the nicotinic a7 agonist, RG3487, for cognitive deficits in schizophrenia. Neuropsychopharmacology 39:1568-1577

Wallace T, Bertrand D (2013a) Alpha7 neuronal nicotinic receptors as a drug target in schizophrenia. Exp Opin Ther Targets 17:139-155

Wallace T, Bertrand D (2013b) Importance of the nicotinic acetylcholine receptor system in the prefrontal cortex Biochem Phamracol 85:1713-1720

Werkheiser J, Sydserff S, Hubbs S, Ding M, Eisman M, Perry D, Williams A, Smith J, Mrzljak L, Maier D (2011) Ultra-low exposure to alpha-7 nicotine acetylcholine receptor partial agonists elicit an improvement in cognition that corresponds with an increase in alpha-7 receptor expression in rodents: implications for low dose clinical efficacy. Neurosci 186:76-87

Williams J, Gibbon M, First M, Spitzer R, Davies M, Borus J, Howes M, Kane J, Pope H Jr, Rounsaville B (1992) The Structured Clinical Interview for the DSM-III-R (SCID 11). Multisite test-retest reliability. Arch Gen Psychiatry 49:630-636

Wing V, Wass C, Soh D, George T (2012) A review of neurobiological vulnerability factors and treatment implications for comorbid tobacco dependence in schizophrenia. Ann NY Acad Sci 1248:89-106

Winterer G (2010) Why do patients with schizophrenia smoke? Curr Opin. Psychiatry 23:112-119

Winterer G, Gallinat J, Brinkmeyer J, Musso F, Kornhuber J, Thuerauf N (2013) Allosteric alpha-7 nicotinic receptor modulation and P50 sensory gating in schizophrenia: A proof-of-mechanisms study. Neuropharmacol 64:197-204

Wurtman R, Regan M, Ulus I, Yu L (2000) Effect of oral CDP-choline on plasma choline and uridine levels in humans. Biochem Pharmacol 60:989-992

Yang Y, Paspalas C, Jin L, Picciotto M, Arnsten A, Wong M (2013) Nicotinic a7 receptors enhance NMDA cognitive circuits in dorsolateral prefrontal cortex. Proc Natl Acad Sci U S A 110:12678-12683

Young J, Geyer M (2013) Evaluating the role of the alpha-7 nicotinic acetylcholine receptor in the pathophysiology and treatment of schizophrenia. Biochem Pharmacol 86:1122-1132

Zeisel S (2000) Choline: an essential nutrient. Nutrition 16:669-671

Zeisel S, Blusztujn J (1994) Choline and human nutrition. Ann Rev Nutr 14:269-296

Zinke W, Roberts M, Guo K, McDonald J, Robertson R, Thiele A (2006) Cholinergic modulation of response properties and orientation tuning of neurons in primary visual cortex of anesthetized Marmoset monkeys. Eur J Neurosci 24:314-328

\section{Submit your next manuscript to BioMed Central and take full advantage of:}

- Convenient online submission

- Thorough peer review

- No space constraints or color figure charges

- Immediate publication on acceptance

- Inclusion in PubMed, CAS, Scopus and Google Scholar

- Research which is freely available for redistribution

Submit your manuscript at www.biomedcentral.com/submit 